\title{
The bZIP Transcription Factor GmbZIP15 Negatively Regulates Salt- and Drought-Stress Responses in Soybean
}

\author{
Man Zhang ${ }^{1}$, Yanhui Liu ${ }^{1}$, Hanyang Cai ${ }^{1}$, Mingliang Guo ${ }^{1}$, Mengnan Chai ${ }^{1}$, Zeyuan She ${ }^{2}$, \\ Li Ye ${ }^{1}$, Yan Cheng ${ }^{1}$, Bingrui Wang ${ }^{3, *}$ and Yuan Qin ${ }^{1,2, * \mathbb{D}}$ \\ 1 Key Lab of Genetics, Breeding and Multiple Utilization of Crops, Ministry of Education, State Key \\ Laboratory of Ecological Pest Control for Fujian and Taiwan Crops, Fujian Provincial Key Laboratory of \\ Haixia Applied Plant Systems Biology, Center for Genomics and Biotechnology, College of Plant Protection, \\ College of Life Sciences, College of Crop Science, Fujian Agriculture and Forestry University, Fuzhou 350002, \\ China; zhangman3043@163.com (M.Z.); yanhuiliu520@gmail.com (Y.L.); caihanyang123@163.com (H.C.); \\ gml604@163.com (M.G.); chaimengnan1@163.com (M.C.); 1180204044@fafu.edu.cn (L.Y.); \\ chengyan1220@hotmail.com (Y.C.) \\ 2 State Key Laboratory for Conservation and Utilization of Subtropical Agro-Bioresources, Guangxi Key Lab \\ of Sugarcane Biology, College of Agriculture, Guangxi University, Nanning 530004, China; szy0809@yeah.net \\ 3 College of Plant Science \& Technology, Huazhong Agricultural University, Wuhan 430070, China \\ * Correspondence: brwang@mail.hzau.edu.cn (B.W.); yuanqin@fafu.edu.cn (Y.Q.)
}

Received: 22 September 2020; Accepted: 18 October 2020; Published: 21 October 2020

\begin{abstract}
Soybean (Glycine max), as an important oilseed crop, is constantly threatened by abiotic stress, including that caused by salinity and drought. bZIP transcription factors (TFs) are one of the largest TF families and have been shown to be associated with various environmental-stress tolerances among species; however, their function in abiotic-stress response in soybean remains poorly understood. Here, we characterized the roles of soybean transcription factor GmbZIP15 in response to abiotic stresses. The transcript level of GmbZIP15 was suppressed under salt- and drought-stress conditions. Overexpression of GmbZIP15 in soybean resulted in hypersensitivity to abiotic stress compared with wild-type (WT) plants, which was associated with lower transcript levels of stress-responsive genes involved in both abscisic acid (ABA)-dependent and ABA-independent pathways, defective stomatal aperture regulation, and reduced antioxidant enzyme activities. Furthermore, plants expressing a functional repressor form of GmbZIP15 exhibited drought-stress resistance similar to WT. RNA-seq and qRT-PCR analyses revealed that GmbZIP15 positively regulates GmSAHH1 expression and negatively regulates GmWRKY12 and GmABF1 expression in response to abiotic stress. Overall, these data indicate that GmbZIP15 functions as a negative regulator in response to salt and drought stresses.
\end{abstract}

Keywords: GmbZIP15; transcription factor; salt stress; drought stress; RNA-seq; soybean

\section{Introduction}

As a result of their sessile nature, plants are subject to variable biotic and abiotic-stress conditions. As the most pertinent abiotic-stress conditions, drought and salinity threaten the growth and productivity of crops. Plants respond and adapt to these stress conditions by activating stress-related pathways, which comprise signal perception and transduction, regulation of gene expression, and biochemical and physiological responses [1]. Signaling pathways, including those involving various phytohormones, multiple secondary metabolism processes, and reactive oxygen species (ROS), are crucial for plant survival under environmental-stress conditions [2-4]. 
Abiotic stress usually leads to the generation of ROS such as hydrogen peroxide $\left(\mathrm{H}_{2} \mathrm{O}_{2}\right)$ and superoxide $\left(\mathrm{O}^{2-}\right)$; however, $\mathrm{ROS}$ overaccumulation is cytotoxic $[5,6]$. To control the level of ROS accumulation under stress conditions, plants have evolved a wide range of antioxidants to scavenge ROS and reinstate cellular redox homeostasis. Previous studies have found that ROS signaling is linked to abscisic acid (ABA), $\mathrm{Ca}^{2+}$ fluxes, and sugar sensing, and is likely to be involved in ABA-dependent signaling pathways activated under abiotic stress [5,7]. Overexpression of GmSIN1 in soybean (Glycine max) promotes root growth and salt tolerance by enhancing cellular ABA and ROS contents [7]. In rice (Oryza sativa), OsCPK12 promotes salt-stress resistance, likely through repression of ROS production and/or the participation of the ABA signaling pathway [8].

ABA is one of the most important stress-related phytohormones and plays a pivotal role in signal transduction during abiotic-stress responses [8,9]. Cellular ABA levels in plants increase in response to abiotic stress, leading to the expression of stress-responsive genes, the regulation of metabolic processes, and the quenching of ROS, thereby maintaining plant cell homeostasis under stress conditions [10]. Recent studies have found that plants respond to abiotic-stress conditions mainly through ABA-dependent and ABA-independent signaling pathways, which are regulated by AREB/ABFs and DREB2A transcription factors (TFs), respectively [11]. In Arabidopsis under abiotic-stress conditions, ABA enacts responses primarily through four bZIP TFs, namely, ABF1, AREB1/ABF2, AREB2/ABF4, and ABF3, the expression of which is activated by SnRK2s [10-14]. Abiotic stress and ABA has also been shown to induce the expression of AREB1/ABF2, AREB2/ABF4, and $A B F 3$ [15], and an increased abundance of these AREB/ABFs in turn increases ABA sensitivity and abiotic-stress resistance $[13,16]$. ABF1 has also been shown to function in drought-stress responses, despite its lower expression level compared to other abiotic-stress-induced AREB/ABFs, and thus areb1areb2abf3abf1 plants display decreased drought resistance compared to areb1areb2abf3 plants regarding primary root growth [10]. DREB2 proteins are members of the AP2/ERF family of plant-specific TFs and function in an ABA-independent manner [11]. Among the DREB2 genes in Arabidopsis, DREB2A is largely induced by drought, salinity, and cold stress [17]. Three DREB homologues, namely, GmDREBa, GmDREBb, and GmDREBc, have been identified in the soybean genome and the transcript levels of GmDREBa and GmDREBb in the leaves of soybean seedlings were shown to increase following salt-, drought-, and cold-stress treatment [18].

Transcription factors are considered to be the most important regulators of gene expression. Several groups of TFs, such as DREB, NAC, MYB, WRKY, and bZIP, are responsible for abiotic-stress responses [19-23]. The bZIP TFs, which represent one of the largest plant TF families, can be divided into different subfamilies depending on the bZIP domain [24]. Plant bZIP TFs play crucial regulatory roles in multiple abiotic-stress resistances $[12,25,26]$. In Arabidopsis, ABI5 expression is regulated by $A B F 3$, which may contribute to salt-stress tolerance [14]. In rice, OsABF1 improves drought tolerance by activating the transcription of COR413-TM1 [12]. Overexpression of the sweet potato (Ipomoea batatas) TF IbABF4 in Arabidopsis resulted in increased ABA sensitivity as well as enhanced drought and salt-stress tolerance [27].

Soybean is one of the most important crops and is widely cultivated worldwide because of its nutritive value. However, soybean growth is threatened by many abiotic-stress factors such as salinity, drought, and extreme temperature. In a previous study, 160 bZIP family members were identified from the soybean genome and were divided into 12 subgroups [24]. Among these, many family members have been characterized to play roles in abiotic-stress responses, including GmbZIP132, GmbZIP110, GmbZIP44, GmbZIP62, and GmbZIP78 [28-30]. However, the function of GmbZIP15, the only member of subfamily $K$, in response to abiotic stress remains poorly understood. In this study, biochemical and physiological analyses were performed to reveal the regulatory roles of GmbZIP15 in abiotic-stress responses. 


\section{Results}

\subsection{GmbZIP15 Expression Pattern in Response to Abiotic-Stress Conditions}

We previously identified 160 bZIP genes from soybean and characterized their expression in response to abiotic stress [24]. Among these genes, the expression of GmbZIP15 was suppressed by drought and flooding stress and it was therefore selected for further investigation. To validate the response of GmbZIP15 to abiotic-stress conditions, we generated soybean plants overexpressing GmbZIP15 (OX-GmbZIP15), and two lines (OE-8, OE-16) with higher expression level were selected for further research (Figure S1). The qRT-PCR analysis was used to determine GmbZIP15 expression patterns in 2-week-old wild-type (WT) and two overexpression lines under salt and drought treatments. Under normal conditions, GmbZIP15 expression level in OX-GmbZIP15 plants was clearly higher than that in WT; however, GmbZIP15 expression in OX-GmbZIP15 plants treated with NaCl and mannitol sharply decreased, but was higher than WT plants by $12 \mathrm{~h}$ and was nearly undetectable by $24 \mathrm{~h}$ post-treatment (Figure S2A,B). In addition, through the GUS staining of 1-week-old pGmbZIP15:GUS transgenic Arabidopsis seedlings grown on media supplemented with $100 \mathrm{mM} \mathrm{NaCl}$ or $200 \mathrm{mM}$ mannitol, GmbZIP15 promoter activity was observed to be significantly decreased in cotyledons and true leaves under $\mathrm{NaCl}$ and mannitol conditions compared to normal conditions (Figure S2C), which was consistent with the results of qRT-PCR (Figure S1A,B). These results suggest that the expression of GmbZIP15 is suppressed by abiotic stress.

\subsection{GmbZIP15 Negatively Regulates Salt and Drought Tolerance in Soybean}

To investigate the role of GmbZIP15 in plant response to salt stress, transgenic soybean plants carrying functional repression of GmbZIP15 (35S:GmbZIP15-SRDX) were obtained and two lines (SRDX-15, SRDX-21) with higher expression levels were selected for further research (Figure S1). WT, OX-GmbZIP15 and 35S:GmbZIP15-SRDX seedlings were treated with $200 \mathrm{mM}$ $\mathrm{NaCl}$. Following 2 weeks of salt treatment, WT and 35S:GmbZIP15-SRDX soybean seedlings exhibited a comparable degree of leaf shedding, whereas OX-GmbZIP15 plants displayed a severe, almost lethal wilt phenotype (Figure 1A). These results suggest that overexpression of GmbZIP15 in soybean causes sensitivity to salt stress.

To test the function of GmbZIP15 in plant drought responses, WT, OX-GmbZIP15 and 35S:GmbZIP15-SRDX seedlings were withheld water for 2 weeks. Compared to WT and 35S:GmbZIP15-SRDX seedlings, OX-GmbZIP15 seedlings were severely wilted and almost all leaves displayed a considerable dehydration phenotype (Figure 2A). To test whether the dehydration phenotype could be rescued, we rewatered the drought-treated plants for 3 days. Although there was slight shedding of the old leaves of WT and 35S:GmbZIP15-SRDX seedlings after rewatering, there was vigorous new leaf growth, suggesting that WT and 35S:GmbZIP15-SRDX plants can recover from such a dehydration phenotype. In contrast, OX-GmbZIP15 seedlings did not display growth recovery after rewatering. Combined, these results further support that GmbZIP15 acts as a potential negative regulator of abiotic-stress response.

In addition, the transcription levels of drought-/salt-tolerance marker genes, including $G m D R E B b$, GmMYB118, and GmWRKY28, were evaluated by qRT-PCR in WT and OX-GmbZIP15 plants. Under mock conditions, the expression levels of each marker were considerably higher in OX-GmbZIP15 plants compared to WT plants (Figure S3A,B). However, under salt stress, the expression levels of GmDREBb, GmMYB118, and GmWRKY28 dramatically decreased in OX-GmbZIP15 plants compared with that in WT plants (Figure S3A). Similarly, under drought stress, the expression levels of $G m D R E B b$, GmMYB118, and GmWRKY28 genes in OX-GmbZIP15 plants also decreased significantly compared with that in WT plants (Figure S3B). These results indicate that GmbZIP15-overexpressing soybean plants are hypersensitive to abiotic stress. 

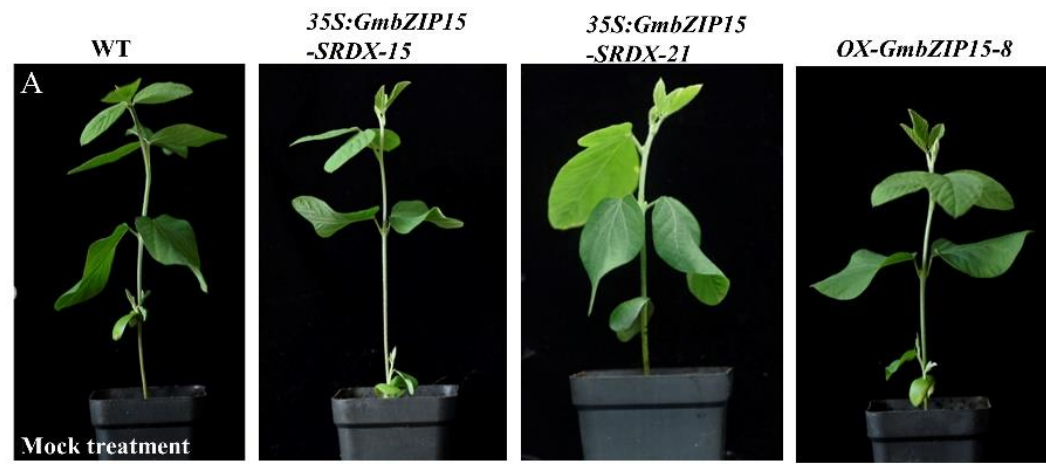

$O X-G m b Z I P 15-16$
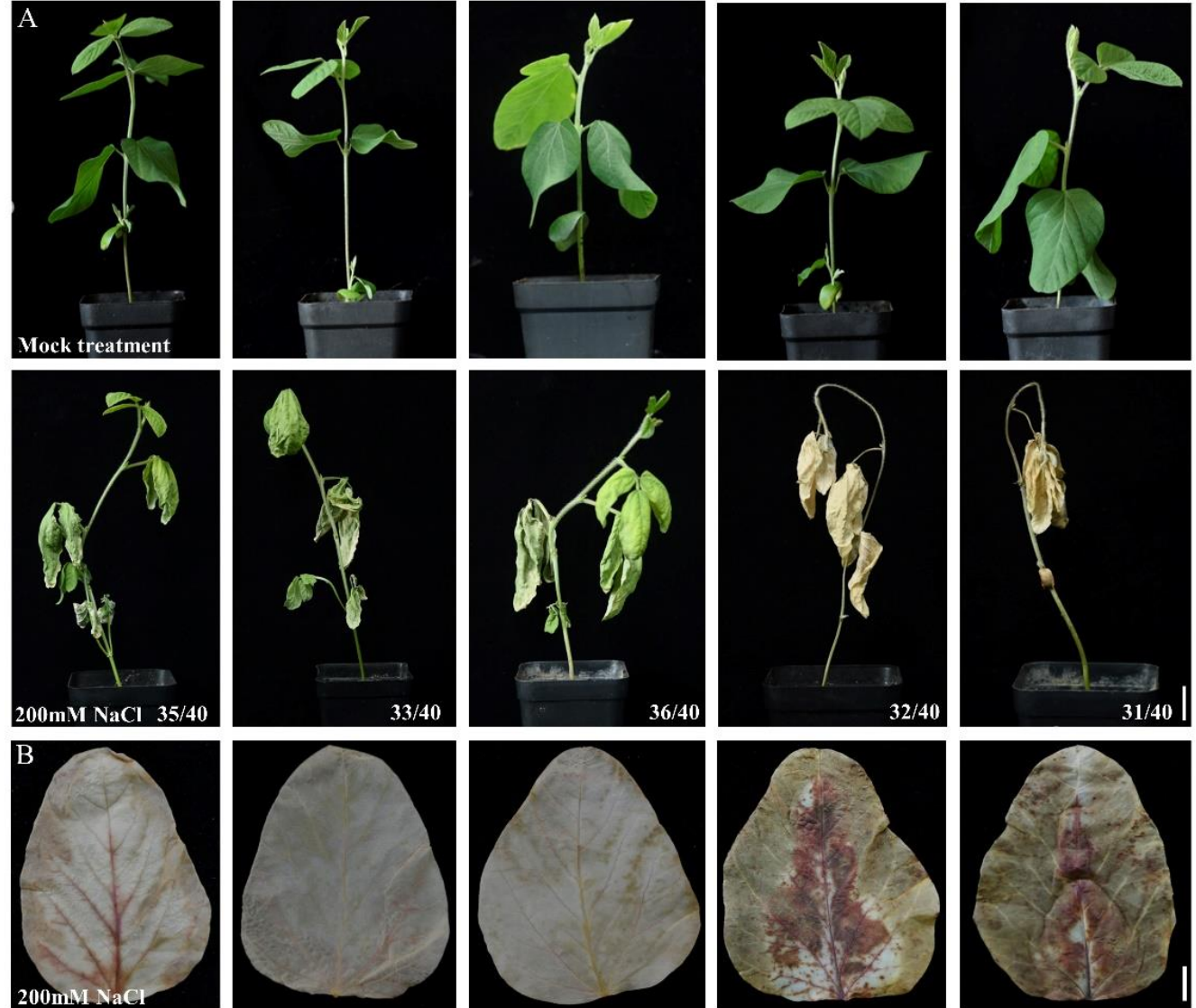

Figure 1. GmbZIP15 negatively regulates salt-stress resistance in soybean. (A) Phenotype observation of transgenic soybean seedlings in response to salt stress. The pictures were obtained before or after $200 \mathrm{mM} \mathrm{NaCl}$ treatment for 2 weeks. Numbers in the panels denote the frequencies of the phenotypes shown. (B) Diaminobenzidine (DAB) staining of the soybean leaves. All the plants were treated with $200 \mathrm{mM} \mathrm{NaCl}$ for 4 days and then the leaves were harvested. The depth of color shows the $\mathrm{H}_{2} \mathrm{O}_{2}$ content in leaves. Bar $=1 \mathrm{~cm}$. 

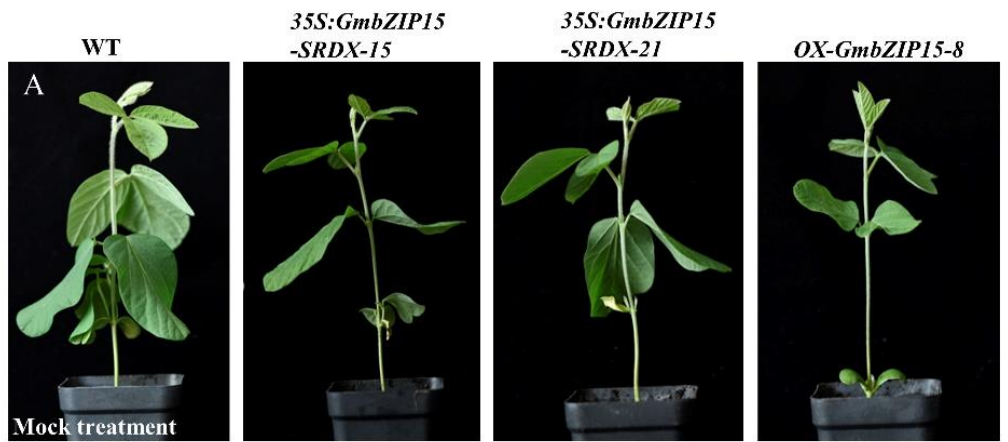

OX-GmbZIP15-16
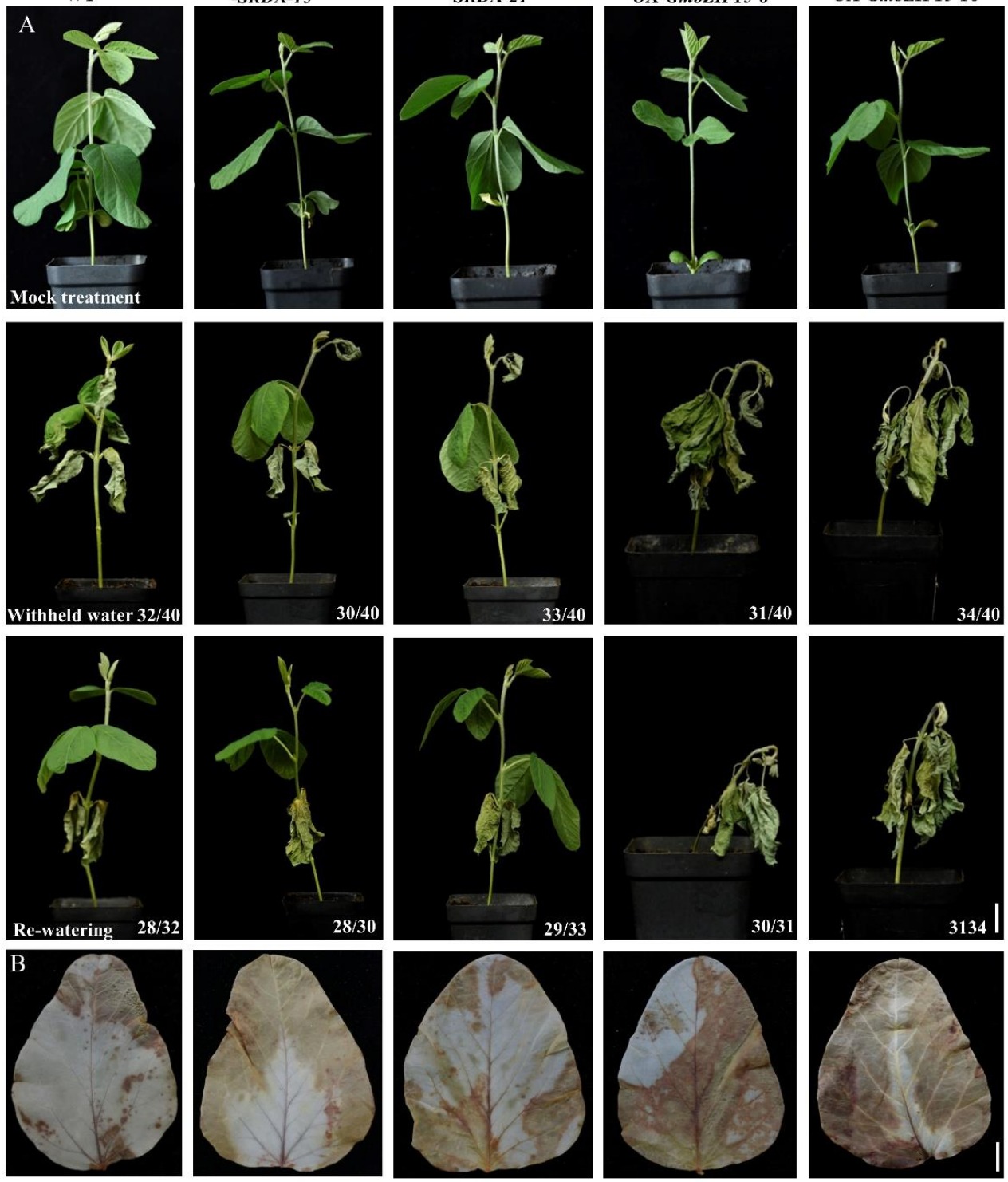

Figure 2. GmbZIP15 negatively regulates drought-stress resistance in soybean. (A) Phenotype observation of transgenic soybean seedlings in response to drought stress. The pictures were obtained under normal conditions; thereafter, the plants were not watered for 2 weeks, then rewatered for 3 days. Numbers in the panels denote the frequencies of the phenotypes shown. (B) DAB staining of the soybean leaves. All the plants were not watered for 4 days and then the leaves were harvested. The depth of color shows the $\mathrm{H}_{2} \mathrm{O}_{2}$ content in the leaves. Bar $=1 \mathrm{~cm}$.

\subsection{GmbZIP15 Depresses the ROS Scavenging Ability of Soybean}

Abiotic stress can lead to damage to plant cells via oxidative stress involving the generation of ROS [31]. Diaminobenzidine (DAB) staining showed that $\mathrm{H}_{2} \mathrm{O}_{2}$ levels were largely increased in the leaves of OX-GmbZIP15 soybean plants compared with WT plants as indicated by the larger amount of reddish-brown precipitate observed following the treatment with $200 \mathrm{mM} \mathrm{NaCl}$ and $300 \mathrm{mM}$ mannitol (Figures 1B and 2B). By contrast, the $\mathrm{H}_{2} \mathrm{O}_{2}$ contents in 35S:GmbZIP15-SRDX soybean plants were comparable with that in WT plants under salt- or drought-stress conditions (Figures 1B and 2B). We further investigated whether altered $\mathrm{H}_{2} \mathrm{O}_{2}$ contents reflected altered ROS-scavenging capability in these plants. For this, the activities of the two main antioxidant enzymes involved in ROS scavenging, namely, peroxidase (POD) and catalase (CAT), were determined in WT, OX-GmbZIP15, 
and 35S:GmbZIP15-SRDX soybean seedlings before and after 24-h treatment with $200 \mathrm{mM} \mathrm{NaCl}$ and $300 \mathrm{mM}$ mannitol. Before stress treatment, OX-GmbZIP15 soybean plant showed higher activities of POD and CAT than WT plants (Figure S4A,B), whereas following salt- and drought-stress treatments, there was a marked decrease in POD and CAT activities in OX-GmbZIP15 soybean plant compared to WT plants (Figure S4A,B). These results indicate that ROS scavenging was depressed in GmbZIP15-overexpressing soybean plants upon abiotic stress.

\subsection{Changes of Stomatal Aperture in GmbZIP15 Transgenic Soybean Plants during Abiotic-Stress Conditions}

Abiotic stress usually leads to a reduction in plant water loss through the regulation of the stomata aperture [32]. Thus, we analyzed stomatal regulation and its possible association with the stress-sensitive phenotype of GmbZIP15 transgenic soybean plants. The stomatal apertures (width/length, W/L) of WT, OX-GmbZIP15, and 35S:GmbZIP15-SRDX soybean plants were measured under control and abiotic-stress conditions. As shown in Figure 3, WT and transgenic soybean plants displayed similar stomatal apertures under control conditions. Moreover, following $200 \mathrm{mM}$ $\mathrm{NaCl}$ and $300 \mathrm{mM}$ mannitol treatments, there were no obvious differences in stomatal apertures between 35S:GmbZIP15-SRDX and WT plants; however, a greater stomatal aperture was observed in OX-GmbZIP15 plants compared to WT and 35S:GmbZIP15-SRDX plants (Figure 3A,B). These data show that there is defective stomatal closure in OX-GmbZIP15 plants upon abiotic stress.
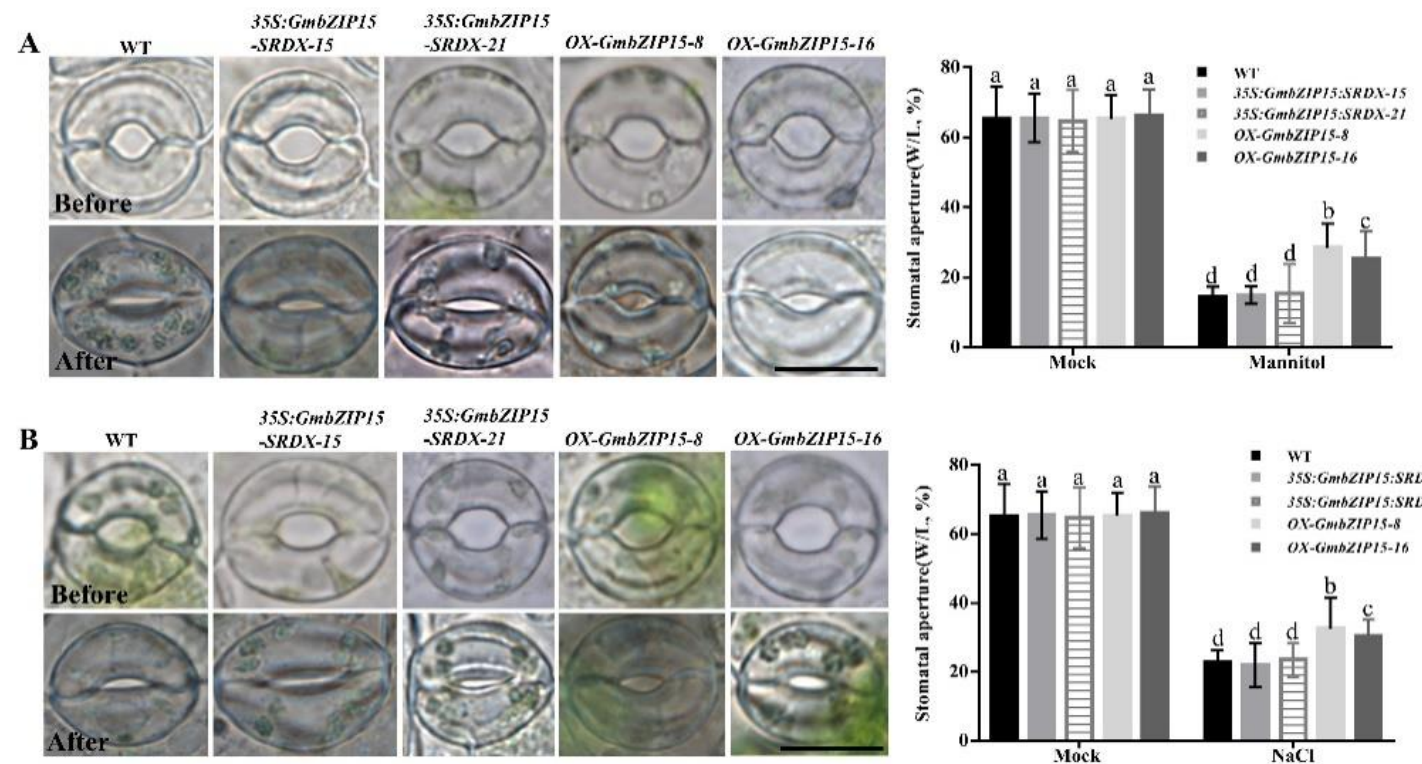

Figure 3. Changes in the stomatal aperture in GmbZIP15 transgenic soybean plants under salt- and drought-stress conditions. (A,B) Comparison of stomatal aperture with width over length before or after $200 \mathrm{mM} \mathrm{NaCl}$ treatment for $1 \mathrm{~h}(\mathbf{A})$ or before or after $300 \mathrm{mM}$ mannitol treatment for $1 \mathrm{~h}(\mathbf{B})$. Data were calculated from 100 stomata of the leaves of three different soybean plants. The experiments were performed three times with similar results. Bar $=10 \mu \mathrm{m}$. Errors bars indicate \pm SD of three biological replicates. Significant differences between samples labeled $a, b$, and c were determined by one-way ANOVA, $p<0.05$.

\subsection{Conservation of GmbZIP15-Mediated Abiotic-Stress Responses in Soybean and Arabidopsis}

To further investigate the function of GmbZIP15 in response to abiotic stress, OX-GmbZIP15 and 35S:GmbZIP15-SRDX transgenic Arabidopsis plants were generated and two lines of each with higher expression levels were selected for further research (Figure 4B). Five-week-old soil-grown WT, OX-GmbZIP15 and 35S:GmbZIP15-SRDX transgenic Arabidopsis plant were watered with $150 \mathrm{mM}$ $\mathrm{NaCl}$. After 2 weeks, approximately 80\% of WT $(n=50)$ and 35S:GmbZIP15-SRDX plants $(n=50)$ remained viable, while nearly $90 \%$ of OX-GmbZIP15 plants $(n=50)$ died (Figure S5A). These results 
indicate that, similar to OX-GmbZIP15 soybean plants, OX-GmbZIP15 Arabidopsis plants were also sensitive to salt stress. Similarly, following a 2-week dehydration treatment of WT, OX-GmbZIP15, and 35S:GmbZIP15-SRDX transgenic Arabidopsis plants, approximately $85 \%$ of WT $(n=50)$ and 35S:GmbZIP15-SRDX $(n=50)$ plants showed some degree of wilting phenotype but remained alive, whereas approximately $90 \%$ of the OX-GmbZIP15 plants $(n=50)$ displayed a severe, near lethal wilting phenotype (Figure S5B). These results suggest that OX-GmbZIP15 overexpression causes similar drought- and salt-stress sensitivity in both Arabidopsis and soybean.

In addition, seed germination efficiency of WT, OX-GmbZIP15, and 35S:GmbZIP15-SRDX Arabidopsis lines were evaluated under control and drought- and salt-stress conditions. For this, seeds of each line were germinated on 1/2 Murashige and Skoog Medium (MS) with or without $150 \mathrm{mM} \mathrm{NaCl}$ or $300 \mathrm{mM}$ mannitol; the growth of two OX-GmbZIP15 lines were inhibited severely (Figure 4A). In addition, the cotyledon greening rate was much lower in OX-GmbZIP15 compared to WT and 35S:GmbZIP15-SRDX transgenic Arabidopsis plants (Figure 4C). Taken together, these results indicate that GmbZIP15 plays a conserved role in drought- and salt-stress responses in both soybean and Arabidopsis.

To further understand the causal factors behind the drought- and salt-stress hypersensitivity of GmbZIP15-overexpressing Arabidopsis plants, we assayed expression levels of several known abiotic-stress-responsive genes in WT and OX-GmbZIP15 transgenic Arabidopsis plants under control and drought- and salt-stress conditions. Transcript levels of each of the analyzed genes, including AtWRKY33, AtCOR6-6, AtDREB2A, and AtRD29A, were suppressed in OX-GmbZIP15 plants compared with WT plants under normal conditions (Figure 4D,E). Under salt stress, the expression levels of AtCOR6-6, AtDREB2A, and AtRD29A were increased in both WT and OX-GmbZIP15 plants following salt-stress treatment, although the magnitude of expression induction was much lower in OX-GmbZIP15 plants (Figure 4D). Similar patterns of repressed expression of abiotic stress-responsive genes were detected in OX-GmbZIP15 plants following drought-stress treatment. The expression levels of AtWRKY33, AtDREB2A, and AtRD29A were induced in both WT and OX-GmbZIP15 plants by drought stress, but to a smaller extent in OX-GmbZIP15 plants (Figure 4E). These results indicate that the drought- and salt-stress hypersensitivity caused by GmbZIP15 overexpression in Arabidopsis may be due to the repressed expression of drought- and salt-responsive genes.

AtbZIP60 is the homologue of GmbZIP15 in Arabidopsis. To investigate the role of AtbZIP60 in response to drought and salt stress, we analyzed the growth of the bzip60 mutant (SALK_050203C) under control and drought- and salt-stress conditions. The results showed that the growth of the bzip60 mutant was significantly repressed as compared to that in WT plants after $150 \mathrm{mM} \mathrm{NaCl}$ or $300 \mathrm{mM}$ mannitol treatment (Figure 4A), which was accompanied by a lower cotyledon greening rate (Figure 4C), suggesting that these mutants are sensitive to drought and salt stress. These results agree with the previous findings that overexpression of AtbZIP60 enhances salt, drought, and cold tolerance in rice [33]. Moreover, these data suggest that the roles of GmbZIP15 and AtbZIP60 in response to abiotic stress have diversified. 

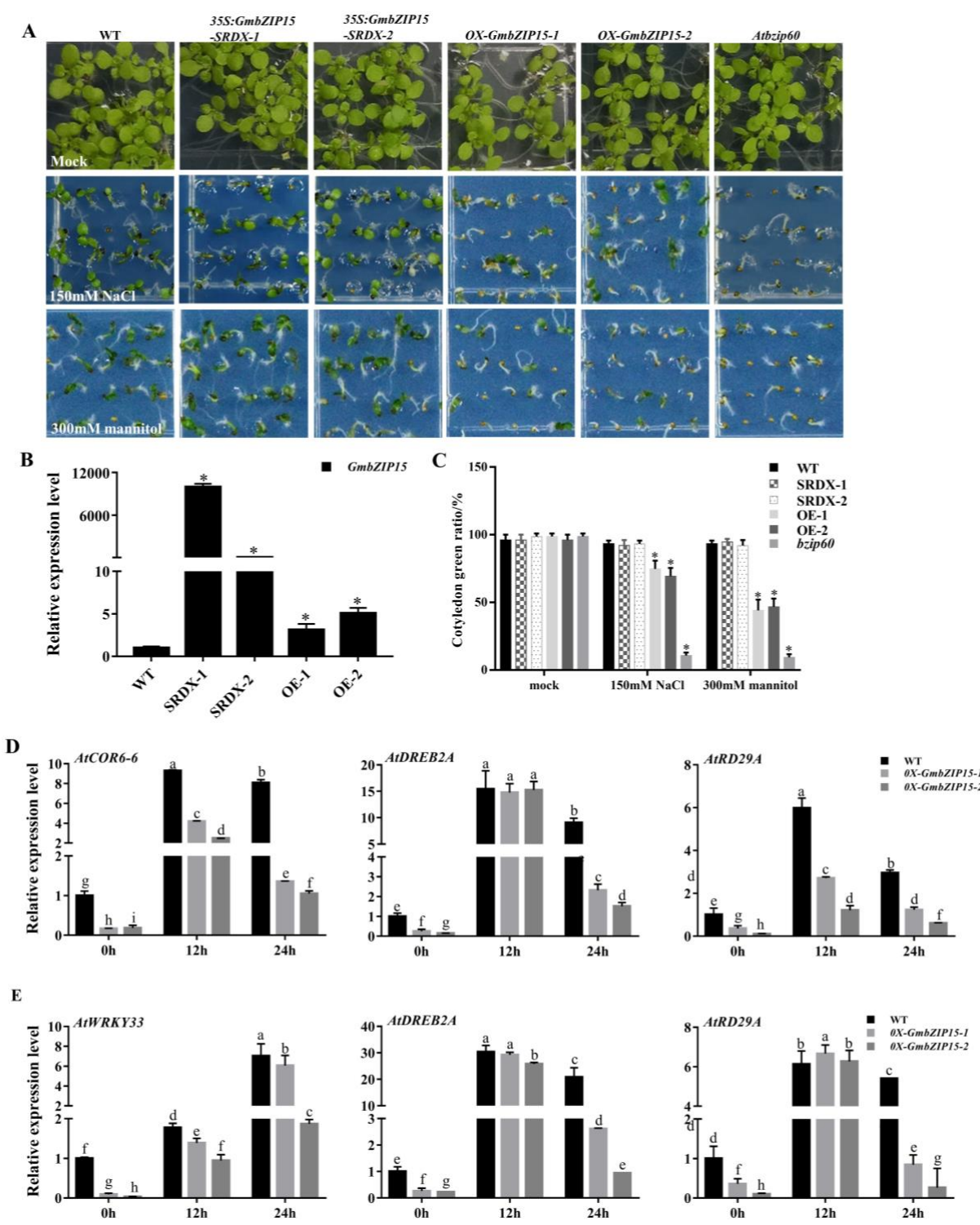

Figure 4. GmbZIP15-overexpressed Arabidopsis is hypersensitive to salt and drought stresses. (A) Phenotype observation of wild-type (WT) and GmbZIP15 transgenic Arabidopsis plants under normal and stress conditions. All the seeds were germinated on the 1/2 Murashige and Skoog Medium (MS) medium under normal conditions or supplemented with $150 \mathrm{mM} \mathrm{NaCl}$ or $300 \mathrm{mM}$ mannitol for 1 week. (B) Transcript level detection of GmbZIP15 in transgenic Arabidopsis plants. (C) Quantification of the cotyledon green rate. (D,E) GmbZIP15 regulates stress-responsive gene expression in WT and GmbZIP15 transgenic Arabidopsis plants. Gene expression levels of AtCOR6-6, AtDREB2A, and AtRD29A were quantified by qRT-PCR assays after $150 \mathrm{mM} \mathrm{NaCl}$ treatment for 0.12 , and $24 \mathrm{~h}(\mathrm{D})$. Gene expression levels of AtWRKY33, AtDREB2A, and AtRD29A were quantified by qRT-PCR assays after $300 \mathrm{mM}$ mannitol treatment for 0.12 , and $24 \mathrm{~h}$ (E). Errors bars indicate \pm SD of three biological replicates. Significant differences between samples labeled a, b, and c were determined by one-way ANOVA, $p<0.05$.

2.6. Transcriptomic Analysis of OX-GmbZIP15 Transgenic Soybean Plants in Response to Salt and Drought Stress

To further reveal the molecular mechanism behind the abiotic-stress sensitivity caused by GmbZIP15 overexpression, we conducted RNA sequencing (RNA-seq) analysis using OX-GmbZIP15-16 (OE) and WT soybean plants grown under either control conditions (mock treated) or treated with $\mathrm{NaCl}$ or mannitol. Three biological replicates were collected for each sample. In OE and 
WT plants, 2229 and 1693 differentially expressed genes (DEGs) were detected respectively, under salt-stress conditions compared to control conditions (fold change: $\geq 2$ and $p \geq 0.05$ ) (Figure 5A). Moreover, 8917 and 4811 DEGs were detected in OE and WT plants, respectively, under drought-stress conditions compared to control conditions (Figure 5A, Table S1). Thus, there were more DEGs induced by both salt and drought stress in OE plants than in WT plants, indicating that GmbZIP15 is responsible for gene expression changes upon salt and drought stress. In addition, we detected 1361 common DEGs (695 upregulated and 546 downregulated) in OE plants upon salt and drought stress (Figure 5B). In order to characterize the DEGs downregulated in the OE line upon salt and drought stresses, we studied their gene annotation (GO) term enrichment compared to that for untreated OE plants. As shown in Figure 5, a number of metabolic processes were enriched in both salt-stress and drought-stress downregulated gene sets in OE plants, such as response to stimuli, oxidation-reduction reactions, photosynthesis, hydrolase activity, phenylalanine biosynthesis, and some secondary metabolism processes (Figure 5C-F). These results imply that the above metabolic pathways are repressed in GmbZIP15-overexpressing soybean plants under abiotic stress.

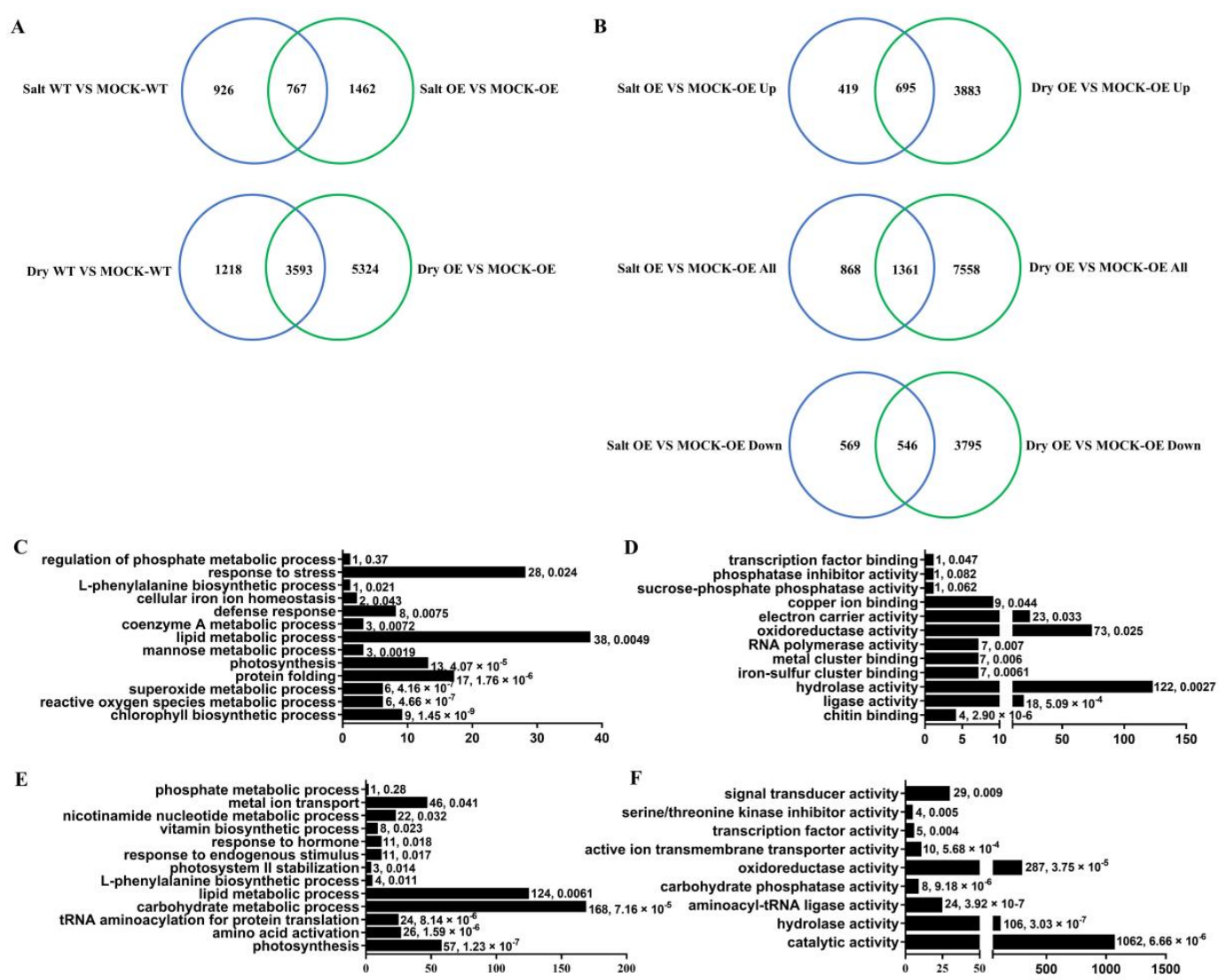

Figure 5. Transcriptomic analysis of OX-GmbZIP15 transgenic soybean plants. (A) Number of specific and common salt- and drought-responsive differentially expressed genes (DEGs) in the WT and OX-GmbZIP15-16 soybean plants. (B) Number of specific and common DEGs in the OX-GmbZIP15-16 soybean plants after salt and drought-stress treatment. (C,D) gene annotation $(\mathrm{GO})$ analysis of the DEGs downregulated in OX-GmbZIP15-16 soybean plants after salt stress: (C) biological process; (D) molecular function. (E,F) GO analysis of the DEGs downregulated in OX-GmbZIP15-16 soybean plants after drought stress; (E) biological process; (F) molecular function. The numbers next to the columns indicate the number of DEGs with corresponding annotation and the $p$-value, respectively $(\mathbf{C}-\mathbf{F})$. 
2.7. GmbZIP15 Regulates the Expression of GmSAHH1, GmABF1, and GmWRKY12 in Soybean in Response to Abiotic Stress

On the basis of the RNA-seq data, five genes (FPKM > 100) with higher expression levels in OE plants compared with WT plants under normal conditions were selected for further analysis. However, only three of these genes (GmSAHH1, GmWRKY12, and GmABF1) were cloned successfully. GmSAHH1 encodes a phosphate dehydrogenase, and expression of its Arabidopsis homologue (ATSAHH1; At4g13940) is detected in developing seeds and some anthers [34]. Moreover, the abundance of ATSAHH1 is reduced in protein extracts from salt-treated cells [35].

We performed a further qRT-PCR analysis to validate the RNA-seq data. Results consistently showed that the expression of GmSAHH1 was higher in OE than in WT soybean plants under normal conditions, but lower in OE than in WT plants under salt- and drought-stress conditions (Figure S6A,B). This repressed expression of GmSAHH1 under abiotic stress was similar to that of GmbZIP15. To further investigate the biological function of GmSAHH1 expression changes under abiotic stress, GmSAHH1-overexpressing (OX-GmSAHH1) transgenic Arabidopsis plants were obtained, and two lines with higher expression levels were selected for further research (Figure 6A) and then subjected to salt- and drought-stress treatments. Before treatment, no obvious morphological differences between 5-week-old WT and OX-GmSAHH1 plants were observed. By contrast, under salt and drought stress, $O X-G m S A H H 1$ transgenic plants exhibited much more pronounced wilting compared with WT plants, which was almost lethal (Figure S5A,B). Seedling growth was also significantly inhibited in OX-GmSAHH1 plants upon salt and drought stress (Figure 6B). The similar salt- and drought-stress hypersensitivity of both GmbZIP15- and GmSAHH1-overexpressing plants suggests that GmbZIP15-regulated responses to salt and drought stress are likely mediated by GmSAHH1 expression activation.

Previous work found that GmWRKY12 positively regulates drought- and salt-stress responses in association with ABA and salicylic acid (SA), and GmWRKY12 overexpression in soybean roots enhances soybean salt and drought tolerance [36]. In our RNA-seq data, GmWRKY12 exhibited higher expression in OE plants than in WT plants under normal conditions and displayed increased expression in OE plants under stress conditions than normal conditions. We conducted a further qRT-PCR analysis and found that the expression of GmWRKY12 was induced by salt and drought treatment in WT and OE plants (Figure S6A,B). Moreover, we cloned an ABA-responsive gene (GmABF1) based on RNA-seq data, and its homologue in Arabidopsis (AtABF1, AT1G49720) is an ABA-dependent TF that regulates the expression of downstream ABA-inducible genes to improve plant drought resistance [10,37]. Our result demonstrated that its expression is induced by salt and drought stress (Figure S6A,B). Furthermore, GmWRKY12-overexpressing (OX-GmWRKY12) and GmABF1-overexpressing (OX-GmABF1) seedlings and plants showed improved salt- and drought-stress tolerance compared to WT plants (Figure 6B and Figure S6A,B), which agreed with the induced expression of GmWRKY12 and GmABF1 under salt and drought stress. These results suggest that GmbZIP15 regulates plant salt- and drought-stress responses partly through inhibiting the expression of GmWRKY12 and GmABF1 upon abiotic stress. 
A

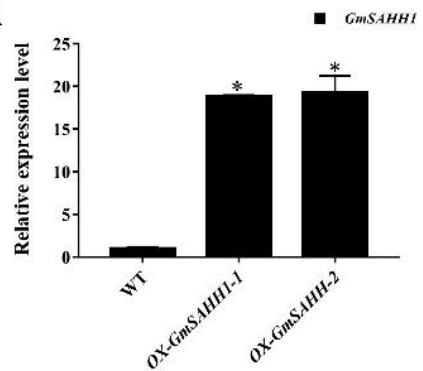

B
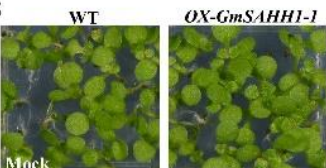

OX-GmSAHHI-
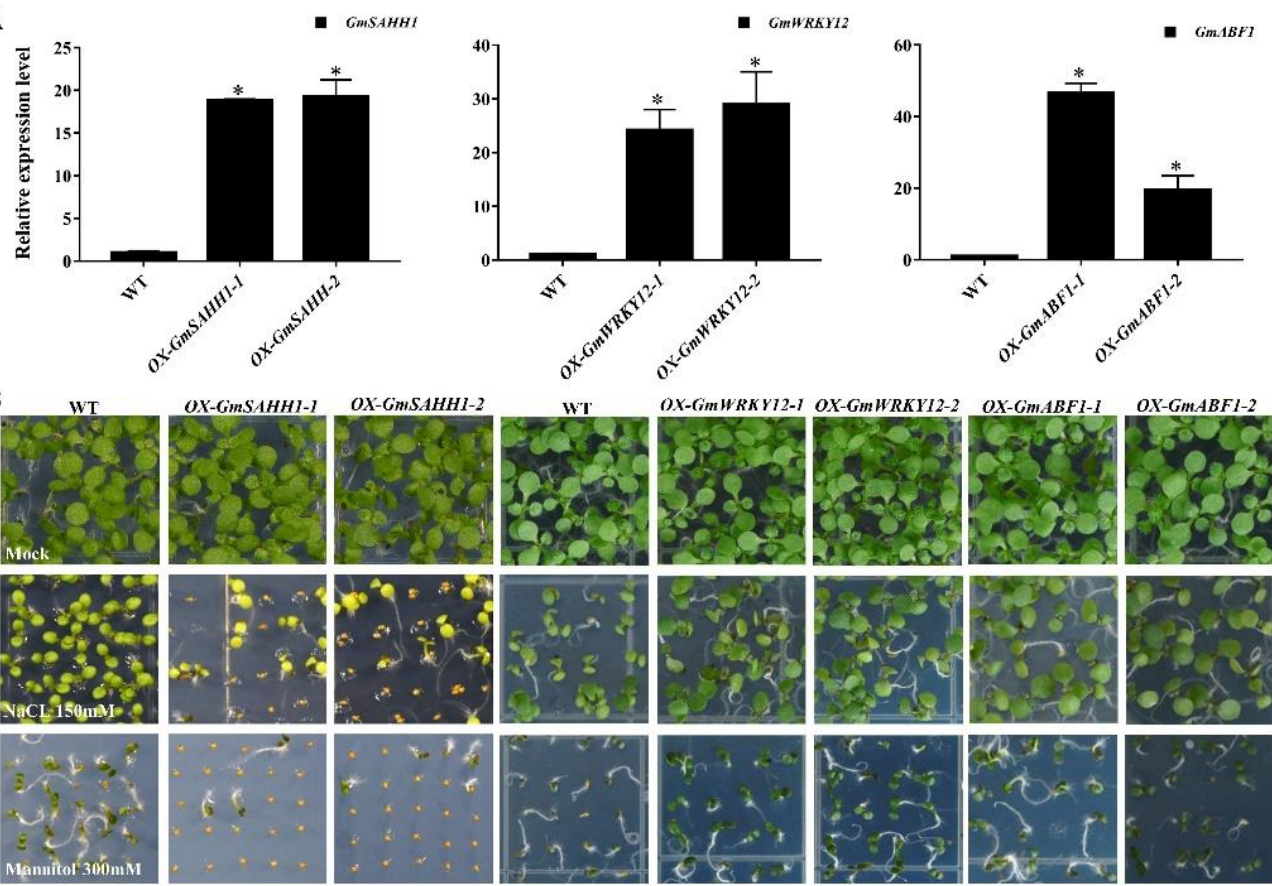

Figure 6. Phenotypic analysis of GmSAHH1-, GmWRKY12-, and GmABF1-overexpressed Arabidopsis plants in response to salt and drought stresses. (A) Transcript level detection of GmSAHH1, GmWRKY12, and GmABF1 in transgenic Arabidopsis plants. Errors bars indicate \pm SD of three biological replicates. Significant differences between samples labeled asterisks were determined by one-way ANOVA, $p<0.05$. (B) Growth observation of WT and overexpression of GmSAHH1, GmWRKY12, and GmABF1 Arabidopsis seedlings under either normal conditions or 150-mM-NaCl- and 300-mM-mannitol-supplemented 1/2 MS medium.

\section{Discussion}

Abiotic stress, including salt and drought stress, has a considerable impact on the quality and yield of agricultural products. The important oilseed crop, soybean, is threatened by diverse categories of abiotic stress. Previous studies have indicated that bZIP TFs play diverse roles in response to various biotic and abiotic stress factors in different crop species, such as rice, soybean, rape, cotton, and maize [38-41]. In this study, a group-K bZIP TF, namely, GmbZIP15, was identified in soybean, and its functions in response to abiotic-stress conditions were analyzed in detail.

AtbZIP60, the Arabidopsis GmbZIP15 homologue, positively modulates plant responses to salt, cold, and abiotic-stress conditions [33]. Here, we found that GmbZIP15 acts as a negative regulator of abiotic-stress responses. The transcription of GmbZIP15 was suppressed by salt and drought stress (Figure S1A,B) and GmbZIP15-overexpressing soybean displayed hypersensitivity to salt and drought stress (Figures 1A and 2A). Our study suggests that GmbZIP15 function in abiotic-stress responses differs from that of AtbZIP60, which is possibly due to the functional divergence of soybean and Arabidopsis during long-term evolution.

To adapt to abiotic stress, especially salt and drought stresses, the plants derive several strategies, including ion regulation and compartmentalization, induction of antioxidant enzymes, plant hormones and regulatory genes [42-44]. For example, the novel soybean regulatory gene GmTIP2;3 could effectively improve the tolerance of yeast to drought stress [43,45]. In addition, when under abiotic-stress conditions, plant endogenous ABA accumulates rapidly and activates the expression of stress-responsive genes, causing many physiological responses [37,46]. It has been demonstrated that ABA plays key roles in maintaining seed dormancy, inhibiting germination, and preventing seedling growth [47], and that abiotic stress is able to induce ABA biosynthesis and trigger ABA-dependent signaling pathways [48]. GmbZIP15 negatively regulates the expression of 
GmABF1, and the overexpression of GmABF1 in Arabidopsis confers increased resistance to salt- and drought-stress conditions (Figure 6B). In addition, GmWRKY12 in association with ABA positively regulates drought- and salt-stress responses, and the overexpression of GmWRKY12 in soybean roots enhances plant salt and drought tolerance [36]. These results indicate a negative regulation of GmbZIP15 for ABA signaling which might via GmABF1 and GmWRKY12 in response to abiotic stress. In addition, the stress-responsive genes AtDREB2A and AtRD29A in OX-GmbZIP15 Arabidopsis plants (Figure 4C,D) and GmDREBb (Figure S2A,B) in OX-GmbZIP15 soybean plants exhibited lower transcript levels than those in WT plants under salt or drought conditions. AREBs and DREB are two groups of TFs that independently regulate the expression of genes involved in ABA-dependent and ABA-independent pathways [11]. The promoter regions of RD29 genes (RD29A and RD29B in Arabidopsis) are targeted by AREBs and DREBs; these genes encode hydrophilic proteins that endow plants with enhanced resistance to abiotic and cold stress [49]. Therefore, our study suggests that GmbZIP15 might act a negative regulator of plant drought- and salt-stress responses through ABA-dependent and ABA-independent pathways.

Abiotic stress potentially impairs plant cellular physiology and biochemistry via the excess generation of ROS $[7,50,51]$. For example, SIWRKY81 improved drought tolerance in tomato plants via the repression of SIP5CS1 transcription and thus reducing proline biosynthesis [52]. In this study, $\mathrm{H}_{2} \mathrm{O}_{2}$ contents sharply increased in OX-GmbZIP15 plants compared to WT plants under droughtand salt-stress conditions (Figures $1 \mathrm{~B}$ and 2B). To control the level of ROS accumulation under stress conditions, plants have evolved a number of antioxidants, such as SOD, POD, and CAT, to scavenge ROS and to restore cellular redox homeostasis [53-57]. With the development of molecular biology, our understanding of molecular and physiology mechanisms is becoming clearer. Our results showed that the activities of POD and CAT were suppressed in OX-GmbZIP15 transgenic soybean plants under salt and drought stress (Figure S2C,D), indicating compromised ROS scavenging capability in OX-GmbZIP15 plants in comparison with WT plants. Therefore, we hypothesize that GmbZIP15 plays a negative role in regulating these ROS-scavenging enzyme systems under abiotic stress.

Previous studies showed that bZIP TFs function in many biotic and abiotic-stress responses in plants through regulating diverse biochemical and physiological pathways $[12,23,39,58]$. RNA- sequencing has been widely used to investigate the molecular processes related to adaptive responses to abiotic stresses and to identify stress-resistance candidate genes by analyzing differences in transcript abundance [44]. In our research, we found that the functional annotation of DEGs that were enriched in the set of downregulated genes in OE plants after salt and drought treatment compared to that in control conditions indicated that, under salt or drought-stress conditions, GmbZIP15-regulated genes were mainly involved in processes such as oxidoreductase activity, phenylalanine biosynthesis, phosphotransferase activity, and some secondary metabolism (Figure 5). As an important polyphenolic secondary metabolite, isoflavones play a crucial role in plants facing diverse environmental-stress conditions [59-61]. PtSAP13, for example, enhances salt tolerance by upregulating the transcript level of stress-responsive genes and inducing multiple biological pathways, such as phenylalanine biosynthesis and dioxygenase activity [62], thus implying that the phenylalanine metabolism process is involved in GmbZIP15-regulated abiotic-stress responses (Figure 5C,E). In addition, photosynthesis is essential for plant growth and is important for plants to maintain a balance between growth and stress responses $[63,64]$. For example, when cyanobacteria grow under stress conditions, photosynthesis-related genes are usually downregulated, whereas stress response-related genes are upregulated [65]. Water deficiency significantly affects photosynthetic characteristics. The drought-tolerant soybean cultivar displayed the maximum values of chlorophyll fluorescence (Fv/Fm, qP, фPSII, and ETR) [66]. When under environmental stress, plants will close their stomata and thus restrict the entry of $\mathrm{CO}_{2}$ into the leaf and reduce the rate of photosynthesis [67]. In this study, many downregulated genes in OX-GmbZIP15 transgenic plants after drought and salt stress were associated with photosynthesis (Figure $5 \mathrm{C}-\mathrm{F}$ ), suggesting that stress adaption was prioritized over photosynthesis; however, impaired stomatal aperture regulation in OX-GmbZIP15 affected plant 
survival. In addition, enzyme-catalyzed removal of $\mathrm{ROS}$ such as superoxide and $\mathrm{H}_{2} \mathrm{O}_{2}$ are important in plant survival under stress conditions [54,63]. As observed here, those genes downregulated in response to abiotic stress represented antioxidant-related processes. Taken together, multiple metabolic pathways seem to be involved in the GmbZIP15-mediated abiotic-stress response network.

In summary, overexpression of GmbZIP15 in soybean resulted in hypersensitivity to salt and drought stresses compared with wild-type (WT) plants, which was associated with lower transcript levels of stress-responsive genes, defective stomatal aperture regulation, and reduced antioxidant enzyme activities. Furthermore, RNA-seq and qRT-PCR analyses revealed that GmbZIP15 positively regulates GmSAHH1 expression and negatively regulates GmWRKY12 and GmABF1 expression in response to salt and drought stresses (Figure 7). These data provided new information for understanding the function of GmbZIP15 and might facilitate the improvement of plant abiotic-stress tolerance through genetic manipulation in the future.

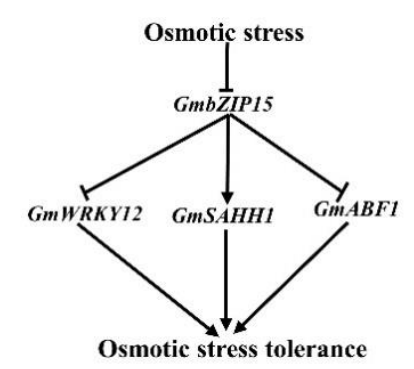

Figure 7. A schematic model of GmbZIP15 mediated abiotic-stress tolerance in soybean. GmbZIP15 negatively modulates the abiotic-stress tolerance: GmbZIP15 positively regulates the expression of GmSAHH1 and negatively regulates the expression of GmWRKY12 and GmABF1 in response to abiotic stresses. The arrows indicate induction or positive modulation; the blunt-end arrows represent block or suppression.

\section{Materials and Methods}

\subsection{Vector Construction and Transformation}

To generate the OX-GmbZIP15 construct, the GmbZIP15 (Glyma.02G161100) coding DNA sequence (CDS) was amplified and the PCR fragments were cloned into the pENTR/D-TOPO vector (Invitrogen, Carlsbad, CA, USA). The pENTR clones were recombined into the destination vector pGWB506 using LR Clonase II (Invitrogen). The resulting construct also contained the selectable marker BAR for glufosinate resistance [68].

35S: GmbZIP15-SRDX was generated by amplifying GmbZIP15 cDNA sequence and an SRDX motif was added to the end of the cDNA sequence (ctagatctggatctagaactccgtttgggtttcgcttaa). The PCR fragment was cloned into the $\mathrm{pENTR/D-TOPO}$ vector (Invitrogen), and the $\mathrm{pENTR/D-TOPO}$ clones were recombined into the destination vector pGWB506 using LR Clonase II (Invitrogen) [69]. The vectors OX-GmbZIP15 and 35S: GmbZIP15-SRDX were then transformed into soybean by agrobacterium-mediated method [70] and the soybean genotype C03-3 was used.

GmWRKY12 (Glyma.01G224800)-, GmABF1 (GmbZIP157, Glyma.20G049200)-, and GmSAHH1 (Glyma.08G108800)-overexpressing vectors were constructed as above [68]. WT Arabidopsis (Col-0) plants were then infected with the transformed bacteria by the floral dip method [71]. All the primers used in the article were listed in Table S2.

\subsection{Plant Materials and Stress Treatments}

Soybean plant seeds including WT (C03-3) and transgenic GmbZIP15 plants were grown for 15 days in pots containing nutritional soil and vermiculite in green house. The seedlings were then exposed to drought and salt stresses. For drought stress, the soybean seedlings were watered with $300 \mathrm{mM}$ mannitol to induce the rapid drought stress. For salt treatment, the seedlings were transferred 
to $200 \mathrm{mM} \mathrm{NaCl}$ solution. All seedlings leaves were harvested at $0,6,12$, and $24 \mathrm{~h}$ under stress conditions for RNA extraction.

Arabidopsis ecotypes Col-0 was used in this study. The T-DNA mutant Atbzip60 (SALK_050203C) was obtained from the Arabidopsis Biological Resource Centre (ABRC). All Seeds were germinated on 1/2 MS medium containing $\mathrm{NaCl}$ or mannitol, after vernalization at $4{ }^{\circ} \mathrm{C}$ for 3 days, the plates containing the seeds were placed in a growth chamber with temperature $22^{\circ} \mathrm{C}$, and a photoperiod of $16 \mathrm{~h} \mathrm{light} / 8 \mathrm{~h}$ dark.

\subsection{Diaminobenzidine (DAB) Staining}

Following previously described methods for hydrogen peroxide $\left(\mathrm{H}_{2} \mathrm{O}_{2}\right)$ detection [72], the soybean leaves after salt and drought treatment for 4 days were immediately vacuum-infiltrated for $20 \mathrm{~min}$ with Tris- $\mathrm{HCl}(\mathrm{pH} 7.4)$ containing $1 \%(w / v)$ DAB. Thereafter, all the leaves were placed in light for $10 \mathrm{~h}$ then boiled for $20 \mathrm{~min}$ in $75 \%$ ethanol.

\subsection{Determination of Stomatal Aperture}

The fully expanded leaves of 2-week-old soybean plants were floated in the stomatal opening buffer with $30 \mathrm{mM} \mathrm{KCl}$ and $10 \mathrm{mM}$ MES-KOH, pH 6.15 for $2 \mathrm{~h}$ under a cool white light, and then $200 \mathrm{mM} \mathrm{NaCl}$ or $300 \mathrm{mM}$ mannitol were added to the opening buffer [22]. After $1 \mathrm{~h}$, the subepidermal peels were stripped and used for stomatal aperture measurements under the microscope. In addition, different phytohormones were added to the opening buffer and the stomatal apertures were observed at different timepoints.

\subsection{RNA Extraction and Quantitative $q R T-P C R$}

Total RNA was extracted using Trizol (Invitrogen, Carlsbad, CA, USA) then reverse-transcribed using the PrimeScript RT-PCR kit (TaKaRa) [71]. The relative expression levels of selected genes were detected by qRT-PCR using Bio-Rad QRT-PCR system (Foster City, CA, USA) and SYBR Premix Ex Taq II (TaKaRa Perfect Real Time). The qRT-PCR program was $95^{\circ} \mathrm{C}$ for $30 \mathrm{~s} ; 40$ cycles of $95^{\circ} \mathrm{C}$ for $5 \mathrm{~s}$ and $60{ }^{\circ} \mathrm{C}$ for $34 \mathrm{~s}$; and $95^{\circ} \mathrm{C}$ for $15 \mathrm{~s} \mathrm{[68].} \mathrm{GmActin} \mathrm{was} \mathrm{used} \mathrm{for} \mathrm{normalization.}$

\subsection{Determination of Antioxidant Enzyme Activity}

The antioxidants including peroxidase (POD) and catalase (CAT) were extracted from approximately $0.1 \mathrm{~g}$ of soybean leaves using $1 \mathrm{~mL}$ extraction solution. The 2-week-old seedlings were treated with $200 \mathrm{mM} \mathrm{NaCl}$ or $300 \mathrm{mM}$ mannitol for $24 \mathrm{~h}$ and then the leaves were harvested. The enzyme activities were measured according to the protocol from Solarbio Biochemical Assay Division.

\subsection{RNA-Seq Data Analysis}

Leaves of 2-week-old soybean plants including WT and OX-GmbZIP15-16 plants treated with $200 \mathrm{mM} \mathrm{NaCl}$ or $300 \mathrm{mM}$ mannitol were harvested at $24 \mathrm{~h}$ for RNA-seq, and three biological replicates were analyzed. The libraries were constructed by BGI (Beijing Genomics Institute) then sequenced. GO analyses were performed using the agriGO online toolkit [http://bioinfo.cau.edu.cn/agriGO/index.php].

Supplementary Materials: The following are available online at http://www.mdpi.com/1422-0067/21/20/7778/s1.

Author Contributions: M.Z. performed vector construction and phenotype analysis. Y.L. performed RNA-seq and soybean transformation. H.C. and M.G. calculated all the data. M.C., Z.S., L.Y. and Y.C. performed qRT-PCR analysis. M.Z. and Y.Q. wrote the manuscript. Y.Q. and B.W. revised the manuscript. All authors have read and agreed to the published version of the manuscript.

Funding: This research was funded by NSFC (U1605212, 31970333) and a Guangxi Distinguished Experts Fellowship.

Conflicts of Interest: The authors declare no conflict of interest. 


\section{Abbreviations}

$\begin{array}{ll}\text { ABA } & \text { Abscisic acid } \\ \text { JA } & \text { Jasmonic acid } \\ \text { SA } & \text { Salicylic acid } \\ \text { ETH } & \text { Ethephon } \\ \text { DREB } & \text { Dehydration responsive element binding protein } \\ \text { NAC } & \text { No Apical Meristem } \\ \text { bZIP } & \text { Basic leucine-zipper } \\ \text { MS } & \text { Murashige and Skoog Medium } \\ \text { GO } & \text { Gene annotation } \\ \text { ETR } & \text { Electron transport rate }\end{array}$

\section{References}

1. Huang, G.T.; Ma, S.L.; Bai, L.P.; Zhang, L.; Ma, H.; Jia, P.; Liu, J.; Zhong, M.; Guo, Z.F. Signal transduction during cold, salt, and drought stresses in plants. Mol. Biol. Rep. 2012, 39, 969-987. [CrossRef] [PubMed]

2. Zhao, M.J.; Yin, L.J.; Ma, J.; Zheng, J.C.; Wang, Y.X.; Lan, J.H.; Fu, J.D.; Chen, M.; Xu, Z.S.; Ma, Y.Z. The Roles of GmERF135 in Improving Salt Tolerance and Decreasing ABA Sensitivity in Soybean. Front. Plant. Sci. 2019, 10, 940. [CrossRef] [PubMed]

3. Huang, Y.; Jiao, Y.; Xie, N.; Guo, Y.; Zhang, F.; Xiang, Z.; Wang, R.; Wang, F.; Gao, Q.; Tian, L.; et al. OsNCED5, a 9-cis-epoxycarotenoid dioxygenase gene, regulates salt and water stress tolerance and leaf senescence in rice. Plant Sci. 2019, 287, 110188. [CrossRef] [PubMed]

4. Ku, Y.S.; Sintaha, M.; Cheung, M.Y.; Lam, H.M. Plant Hormone Signaling Crosstalks between Biotic and Abiotic Stress Responses. Int. J. Mol. Sci. 2018, 19, 3206. [CrossRef] [PubMed]

5. de Carvalho, M.H.C. Drought stress and reactive oxygen species. Plant Signal. Behav. 2014, 3, 156-165. [CrossRef] [PubMed]

6. Miller, G.A.D.; Suzuki, N.; Ciftci-Yilmaz, S.; Mittler, R.O.N. Reactive oxygen species homeostasis and signalling during drought and salinity stresses. Plant Cell Environ. 2010, 33, 453-467. [CrossRef]

7. Li, S.; Wang, N.; Ji, D.; Zhang, W.; Wang, Y.; Yu, Y.; Zhao, S.; Lyu, M.; You, J.; Zhang, Y.; et al. A GmSIN1/GmNCED3s/GmRbohBs Feed-Forward Loop Acts as a Signal Amplifier That Regulates Root Growth in Soybean Exposed to Salt Stress. Plant Cell 2019, 31, 2107-2130. [CrossRef]

8. Asano, T.; Hayashi, N.; Kobayashi, M.; Aoki, N.; Miyao, A.; Mitsuhara, I.; Ichikawa, H.; Komatsu, S.; Hirochika, H.; Kikuchi, S.; et al. A rice calcium-dependent protein kinase OsCPK12 oppositely modulates salt-stress tolerance and blast disease resistance. Plant J. 2012, 69, 26-36. [CrossRef]

9. Gao, Y.F.; Liu, J.K.; Yang, F.M.; Zhang, G.Y.; Wang, D.; Zhang, L.; Ou, Y.B.; Yao, Y.A. The WRKY transcription factor WRKY8 promotes resistance to pathogen infection and mediates drought and salt stress tolerance in Solanum lycopersicum. Physiol. Plant. 2019. [CrossRef]

10. Yoshida, T.; Fujita, Y.; Maruyama, K.; Mogami, J.; Todaka, D.; Shinozaki, K.; Yamaguchi-Shinozaki, K. Four Arabidopsis AREB/ABF transcription factors function predominantly in gene expression downstream of SnRK2 kinases in abscisic acid signalling in response to osmotic stress. Plant Cell Environ. 2015, 38, 35-49. [CrossRef]

11. Yoshida, T.; Mogami, J.; Yamaguchi-Shinozaki, K. ABA-dependent and ABA-independent signaling in response to osmotic stress in plants. Curr. Opin. Plant Biol. 2014, 21, 133-139. [CrossRef] [PubMed]

12. Zhang, C.; Li, C.; Liu, J.; Lv, Y.; Yu, C.; Li, H.; Zhao, T.; Liu, B. The OsABF1 transcription factor improves drought tolerance by activating the transcription of COR413-TM1 in rice. J. Exp. Bot. 2017, 68, 4695-4707. [CrossRef] [PubMed]

13. Kim, S.; Kang, J.Y.; Cho, D.I.; Park, J.H.; Kim, S.Y. ABF2, an ABRE-binding bZIP factor, is an essential component of glucose signaling and its overexpression affects multiple stress tolerance. Plant J. 2004, 40, 75-87. [CrossRef] [PubMed]

14. Chang, H.C.; Tsai, M.C.; Wu, S.S.; Chang, I.F. Regulation of ABI5 expression by ABF3 during salt stress responses in Arabidopsis thaliana. Bot. Stud. 2019, 60, 16. [CrossRef] 
15. Fujita, Y.; Fujita, M.; Satoh, R.; Maruyama, K.; Parvez, M.M.; Seki, M.; Hiratsu, K.; Ohme-Takagi, M.; Shinozaki, K.; Yamaguchi-Shinozaki, K. AREB1 Is a Transcription Activator of Novel ABRE-Dependent ABA Signaling that Enhances Drought Stress Tolerance in Arabidopsis. Plant Cell 2005, 17, 3470-3488. [CrossRef]

16. Kang, J.-Y.; Choi, H.-I.; Im, M.-Y.; Kim, S.Y. Arabidopsis Basic Leucine Zipper Proteins That Mediate Stress-Responsive Abscisic Acid Signaling. Plant Cell 2002, 14, 343-357. [CrossRef]

17. Sakuma, Y.; Liu, Q.; Dubouzet, J.G.; Abe, H.; Shinozaki, K.; Yamaguchi-Shinozaki, K. DNA-binding specificity of the ERF/AP2 domain of Arabidopsis DREBs, transcription factors involved in dehydration- and cold-inducible gene expression. Biochem. Biophys. Res. Commun. 2002, 290, 998-1009. [CrossRef]

18. Li, X.-P.; Tian, A.-G.; Luo, G.-Z.; Gong, Z.-Z.; Zhang, J.-S.; Chen, S.-Y. Soybean DRE-binding transcription factors that are responsive to abiotic stresses. Theor. Appl. Genet. 2005, 110, 1355-1362. [CrossRef]

19. Hao, Y.J.; Wei, W.; Song, Q.X.; Chen, H.W.; Zhang, Y.Q.; Wang, F.; Zou, H.F.; Lei, G.; Tian, A.G.; Zhang, W.K.; et al. Soybean NAC transcription factors promote abiotic stress tolerance and lateral root formation in transgenic plants. Plant J. 2011, 68, 302-313. [CrossRef]

20. Kidokoro, S.; Watanabe, K.; Ohori, T.; Moriwaki, T.; Maruyama, K.; Mizoi, J.; Myint Phyu Sin Htwe, N.; Fujita, Y.; Sekita, S.; Shinozaki, K.; et al. Soybean DREB1/CBF-type transcription factors function in heat and drought as well as cold stress-responsive gene expression. Plant J. 2015, 81, 505-518. [CrossRef]

21. Li, X.W.; Wang, Y.; Yan, F.; Li, J.W.; Zhao, Y.; Zhao, X.; Zhai, Y.; Wang, Q.Y. Overexpression of soybean R2R3-MYB transcription factor, GmMYB12B2, and tolerance to UV radiation and salt stress in transgenic Arabidopsis. Genet. Mol. Res. 2016, 15. [CrossRef]

22. Li, J.; Besseau, S.; Toronen, P.; Sipari, N.; Kollist, H.; Holm, L.; Palva, E.T. Defense-related transcription factors WRKY70 and WRKY54 modulate osmotic stress tolerance by regulating stomatal aperture in Arabidopsis. New Phytol. 2013, 200, 457-472. [CrossRef] [PubMed]

23. Yang, S.; Xu, K.; Chen, S.; Li, T.; Xia, H.; Chen, L.; Liu, H.; Luo, L. A stress-responsive bZIP transcription factor OsbZIP62 improves drought and oxidative tolerance in rice. BMC Plant Biol. 2019, 19, 260. [CrossRef] [PubMed]

24. Zhang, M.; Liu, Y.; Shi, H.; Guo, M.; Chai, M.; He, Q.; Yan, M.; Cao, D.; Zhao, L.; Cai, H.; et al. Evolutionary and expression analyses of soybean basic Leucine zipper transcription factor family. BMC Genomics 2018, 19, 159. [CrossRef] [PubMed]

25. Gaguancela, O.A.; Zuniga, L.P.; Arias, A.V.; Halterman, D.; Flores, F.J.; Johansen, I.E.; Wang, A.; Yamaji, Y.; Verchot, J. The IRE1/bZIP60 Pathway and Bax Inhibitor 1 Suppress Systemic Accumulation of Potyviruses and Potexviruses in Arabidopsis and Nicotiana benthamiana Plants. Mol. Plant Microbe Interact. 2016, 29, 750-766. [CrossRef]

26. Hobo, T.; Kowyama, Y.; Hattori, T. A bZIP factor, TRAB1, interacts with VP1 and mediates abscisic acid-induced transcription. Proc. Natl. Acad. Sci. USA 1999, 96, 15348-15353. [CrossRef]

27. Wang, W.; Qiu, X.; Yang, Y.; Kim, H.S.; Jia, X.; Yu, H.; Kwak, S.S. Sweetpotato bZIP Transcription Factor IbABF4 Confers Tolerance to Multiple Abiotic Stresses. Front. Plant Sci. 2019, 10, 630. [CrossRef] [PubMed]

28. Liao, Y.; Zhang, J.S.; Chen, S.Y.; Zhang, W.K. Role of soybean GmbZIP132 under abscisic acid and salt stresses. J. Int. Plant Biol. 2008, 50, 221-230. [CrossRef] [PubMed]

29. Xu, Z.; Ali, Z.; Xu, L.; He, X.; Huang, Y.; Yi, J.; Shao, H.; Ma, H.; Zhang, D. The nuclear protein GmbZIP110 has transcription activation activity and plays important roles in the response to salinity stress in soybean. Sci. Rep. 2016, 6, 20366. [CrossRef] [PubMed]

30. Liao, Y.; Zou, H.F.; Wei, W.; Hao, Y.J.; Tian, A.G.; Huang, J.; Liu, Y.F.; Zhang, J.S.; Chen, S.Y. Soybean GmbZIP44, GmbZIP62 and GmbZIP78 genes function as negative regulator of ABA signaling and confer salt and freezing tolerance in transgenic Arabidopsis. Planta 2008, 228, 225-240. [CrossRef]

31. Xiong, L.; Schumaker, K.S.; Zhu, J.K. Cell signaling during cold, drought, and salt stress. Plant Cell 2002, 14, S165-S183. [CrossRef] [PubMed]

32. Verslues, P.E.; Agarwal, M.; Katiyar-Agarwal, S.; Zhu, J.; Zhu, J.K. Methods and concepts in quantifying resistance to drought, salt and freezing, abiotic stresses that affect plant water status. Plant J. 2006, 45, 523-539. [CrossRef] [PubMed]

33. Tang, W.; Page, M. Transcription factor AtbZIP60 regulates expression of $\mathrm{Ca}^{2+}$-dependent protein kinase genes in transgenic cells. Mol. Biol. Rep. 2013, 40, 2723-2732. [CrossRef] [PubMed] 
34. Sujatha, T.; Sivanandan, C.; Bhat, S.; Srinivasan, R. In silico and deletion analysis of upstream promoter fragment of S-Adenosyl Homocysteine Hydrolase (SAHH1) gene of Arabidopsis leads to the identification of a fragment capable of driving gene expression in developing seeds and anthers. J. Plant Biochem. Biotechnol. 2009, 18, 13-20. [CrossRef]

35. Ndimba, B.K.; Chivasa, S.; Simon, W.J.; Slabas, A.R. Identification ofArabidopsis salt and osmotic stress responsive proteins using two-dimensional difference gel electrophoresis and mass spectrometry. Proteomics 2005, 5, 4185-4196. [CrossRef] [PubMed]

36. Shi, W.Y.; Du, Y.T.; Ma, J.; Min, D.H.; Jin, L.G.; Chen, J.; Chen, M.; Zhou, Y.B.; Ma, Y.Z.; Xu, Z.S.; et al. The WRKY Transcription Factor GmWRKY12 Confers Drought and Salt Tolerance in Soybean. Int. J. Mol. Sci. 2018, 19, 4087. [CrossRef] [PubMed]

37. Wang, X.; Wang, Y.; Wang, L.; Liu, H.; Zhang, B.; Cao, Q.; Liu, X.; Lv, Y.; Bi, S.; Zhang, S.; et al. Arabidopsis PCaP2 Functions as a Linker Between ABA and SA Signals in Plant Water Deficit Tolerance. Front. Plant Sci. 2018, 9, 578. [CrossRef]

38. Gao, S.Q.; Chen, M.; Xu, Z.S.; Zhao, C.P.; Li, L.; Xu, H.J.; Tang, Y.M.; Zhao, X.; Ma, Y.Z. The soybean GmbZIP1 transcription factor enhances multiple abiotic stress tolerances in transgenic plants. Plant Mol. Biol. 2011, 75, 537-553. [CrossRef]

39. Miyamoto, K.; Nishizawa, Y.; Minami, E.; Nojiri, H.; Yamane, H.; Okada, K. Overexpression of the bZIP transcription factor OsbZIP79 suppresses the production of diterpenoid phytoalexin in rice cells. J. Plant Physiol. 2015, 173, 19-27. [CrossRef]

40. Liu, J.; Chen, N.; Chen, F.; Cai, B.; Dal Santo, S.; Tornielli, G.B.; Pezzotti, M.; Cheng, Z.M. Genome-wide analysis and expression profile of the bZIP transcription factor gene family in grapevine (Vitis vinifera). BMC Genom. 2014, 15, 281. [CrossRef]

41. Dong, Q.; Xu, Q.; Kong, J.; Peng, X.; Zhou, W.; Chen, L.; Wu, J.; Xiang, Y.; Jiang, H.; Cheng, B. Overexpression of ZmbZIP22 gene alters endosperm starch content and composition in maize and rice. Plant Sci. 2019, 283, 407-415. [CrossRef] [PubMed]

42. Tang, X.; Mu, X.; Shao, H.; Wang, H.; Brestic, M. Global plant-responding mechanisms to salt stress: Physiological and molecular levels and implications in biotechnology. Crit. Rev. Biotechnol. 2015, 35, 425-437. [CrossRef] [PubMed]

43. Agarwal, P.K.; Shukla, P.S.; Gupta, K.; Jha, B. Bioengineering for Salinity Tolerance in Plants: State of the Art. Mol. Biotechnol. 2013, 54, 102-123. [CrossRef] [PubMed]

44. Guo, H.; Zhang, L.; Cui, Y.N.; Wang, S.M.; Bao, A.K. Identification of candidate genes related to salt tolerance of the secretohalophyte Atriplex canescens by transcriptomic analysis. BMC Plant Biol. 2019, 19, 213. [CrossRef]

45. Dayong, Z.; Jinfeng, T.; Xiaolan, H.; Zhaolong, X.; Ling, X.; Peipei, W.; Yihong, H.; Marian, B.; Hongxiang, M.; Hongbo, S. A Novel Soybean Intrinsic Protein Gene, GmTIP2;3, Involved in Responding to Osmotic Stress. Front. Plant Sci. 2016, 6, 1237.

46. Zhang, Y.; Kang, E.; Yuan, M.; Fu, Y.; Zhu, L. PCaP2 regulates nuclear positioning in growing Arabidopsis thaliana root hairs by modulating filamentous actin organization. Plant Cell Rep. 2015, 34, 1317-1330. [CrossRef]

47. Finkelstein, R.R.; Gampala, S.S.; Rock, C.D. Abscisic acid signaling in seeds and seedlings. Plant Cell 2002, 14, S15-S45. [CrossRef]

48. Zhu, J.K. Salt and drought stress signal transduction in plants. Annu. Rev. Plant Biol. 2002, 53, 247-273. [CrossRef]

49. Jia, H.; Zhang, S.; Ruan, M.; Wang, Y.; Wang, C. Analysis and application of RD29 genes in abiotic stress response. Acta Physiol. Plant. 2012, 34, 1239-1250. [CrossRef]

50. Luan, Q.; Chen, C.; Liu, M.; Li, Q.; Wang, L.; Ren, Z. CsWRKY50 mediates defense responses to Pseudoperonospora cubensis infection in Cucumis sativus. Plant Sci. 2019, 279, 59-69. [CrossRef]

51. Xu, Z.; Raza, Q.; Xu, L.; He, X.; Huang, Y.; Yi, J.; Zhang, D.; Shao, H.B.; Ma, H.; Ali, Z. GmWRKY49, a Salt-Responsive Nuclear Protein, Improved Root Length and Governed Better Salinity Tolerance in Transgenic Arabidopsis. Front. Plant Sci. 2018, 9, 809. [CrossRef] [PubMed]

52. Li, X.; Wan, H.; Zhou, G.; Cheng, Y.; Ahammed, G.J. SIWRKY81 reduces drought tolerance by attenuating proline biosynthesis in tomato. Sci. Hortic. 2020, 270, 109444.

53. Alscher, R.G.; Erturk, N.; Heath, L.S. Role of superoxide dismutases (SODs) in controlling oxidative stress in plants. J. Exp. Bot. 2002, 53, 1331-1341. [CrossRef] [PubMed] 
54. Cheng, Q.; Dong, L.; Gao, T.; Liu, T.; Li, N.; Wang, L.; Chang, X.; Wu, J.; Xu, P.; Zhang, S. The bHLH transcription factor GmPIB1 facilitates resistance to Phytophthora sojae in Glycine max. J. Exp. Bot. 2018, 69, 2527-2541. [CrossRef]

55. Bechtold, U.; Albihlal, W.S.; Lawson, T.; Fryer, M.J.; Sparrow, P.A.; Richard, F.; Persad, R.; Bowden, L.; Hickman, R.; Martin, C.; et al. Arabidopsis HEAT SHOCK TRANSCRIPTION FACTORA1b overexpression enhances water productivity, resistance to drought, and infection. J. Exp. Bot. 2013, 64, 3467-3481. [CrossRef]

56. Yu, H.; Gao, Q.; Dong, S.; Zhou, J.; Ye, Z.; Lan, Y. Effects of dietary n-3 highly unsaturated fatty acids (HUFAs) on growth, fatty acid profiles, antioxidant capacity and immunity of sea cucumber Apostichopus japonicus (Selenka). Fish Shellfish Immunol. 2016, 54, 211-219. [CrossRef]

57. Ranjan, A.; Jayaraman, D.; Grau, C.; Hill, J.H.; Whitham, S.A.; Ane, J.M.; Smith, D.L.; Kabbage, M. The pathogenic development of Sclerotinia sclerotiorum in soybean requires specific host NADPH oxidases. Mol. Plant Pathol. 2018, 19, 700-714. [CrossRef]

58. Li, Q.; Wu, Q.; Wang, A.; Lv, B.; Dong, Q.; Yao, Y.; Wu, Q.; Zhao, H.; Li, C.; Chen, H.; et al. Tartary buckwheat transcription factor FtbZIP83 improves the drought/salt tolerance of Arabidopsis via an ABA-mediated pathway. Plant Physiol. Biochem. 2019, 144, 312-323. [CrossRef]

59. Wang, Z.; Wang, S.; Xiao, Y.; Li, Z.; Wu, M.; Xie, X.; Li, H.; Mu, W.; Li, F.; Liu, P.; et al. Functional characterization of a HD-ZIP IV transcription factor NtHDG2 in regulating flavonols biosynthesis in Nicotiana tabacum. Plant Physiol. Biochem. 2020, 146, 259-268. [CrossRef]

60. Yan, J.; Wang, B.; Jiang, Y.; Cheng, L.; Wu, T. GmFNSII-controlled soybean flavone metabolism responds to abiotic stresses and regulates plant salt tolerance. Plant Cell Physiol. 2014, 55, 74-86. [CrossRef]

61. Jeong, Y.J.; An, C.H.; Park, S.C.; Pyun, J.W.; Lee, J.; Kim, S.W.; Kim, H.S.; Kim, H.; Jeong, J.C.; Kim, C.Y. Methyl Jasmonate Increases Isoflavone Production in Soybean Cell Cultures by Activating Structural Genes Involved in Isoflavonoid Biosynthesis. J. Agric. Food Chem. 2018, 66, 4099-4105. [CrossRef]

62. Li, J.; Sun, P.; Xia, Y.; Zheng, G.; Sun, J.; Jia, H. A Stress-Associated Protein, PtSAP13, From Populus trichocarpa Provides Tolerance to Salt Stress. Int. J. Mol. Sci. 2019, 20, 5782. [CrossRef]

63. Liu, W.; Zhao, B.G.; Chao, Q.; Wang, B.; Zhang, Q.; Zhang, C.; Li, S.; Jin, F.; Yang, D.; Li, X. Function analysis of ZmNAC33, a positive regulator in drought stress response in Arabidopsis. Plant Physiol. Biochem. 2019, 145, 174-183. [CrossRef] [PubMed]

64. Mutava, R.N.; Prince, S.J.K.; Syed, N.H.; Song, L.; Valliyodan, B.; Chen, W.; Nguyen, H.T. Understanding abiotic stress tolerance mechanisms in soybean: A comparative evaluation of soybean response to drought and flooding stress. Plant Physiol. Biochem. 2015, 86, 109-120. [CrossRef]

65. Ge, H.; Fang, L.; Huang, X.; Wang, J.; Chen, W.; Liu, Y.; Zhang, Y.; Wang, X.; Xu, W.; He, Q.; et al. Translating Divergent Environmental Stresses into a Common Proteome Response through the Histidine Kinase 33 (Hik33) in a Model Cyanobacterium. Mol. Cell. Proteomics 2017, 16, 1258-1274. [CrossRef] [PubMed]

66. Iqbal, N.; Hussain, S.; Raza, M.A.; Yang, C.Q.; Safdar, M.E.; Brestic, M.; Aziz, A.; Hayyat, M.S.; Asghar, M.A.; Wang, X.C. Drought Tolerance of Soybean (Glycine max L. Merr.) by Improved Photosynthetic Characteristics and an Efficient Antioxidant Enzyme Activities Under a Split-Root System. Front. Physiol. 2019, 10, 786. [CrossRef]

67. Zhang, F.; Zhu, G.; Du, L.; Shang, X.; Cheng, C.; Yang, B.; Hu, Y.; Cai, C.; Guo, W. Genetic regulation of salt stress tolerance revealed by RNA-Seq in cotton diploid wild species, Gossypium davidsonii. Sci. Rep. 2016, 6, 20582. [CrossRef] [PubMed]

68. Cai, H.; Zhao, L.; Wang, L.; Zhang, M.; Su, Z.; Cheng, Y.; Zhao, H.; Qin, Y. ERECTA signaling controls Arabidopsis inflorescence architecture through chromatin-mediated activation of PRE1 expression. New Phytol. 2017, 214, 1579-1596. [CrossRef] [PubMed]

69. Zhao, L.; Cai, H.; Su, Z.; Wang, L.; Huang, X.; Zhang, M.; Chen, P.; Dai, X.; Zhao, H.; Palanivelu, R.; et al. KLU suppresses megasporocyte cell fate through SWR1-mediated activation of WRKY28 expression in Arabidopsis. Proc. Natl. Acad. Sci. USA 2018, 115, E526-E535. [CrossRef]

70. Yang, X.; Yang, J.; Wang, Y.; He, H.; Niu, L.; Guo, D.; Xing, G.; Zhao, Q.; Zhong, X.; Sui, L.; et al. Enhanced resistance to sclerotinia stem rot in transgenic soybean that overexpresses a wheat oxalate oxidase. Transgenic Res. 2019, 28, 103-114. [CrossRef] 
71. Cai, H.; Zhang, M.; Chai, M.; He, Q.; Huang, X.; Zhao, L.; Qin, Y. Epigenetic regulation of anthocyanin biosynthesis by an antagonistic interaction between H2A.Z and H3K4me3. New Phytol. 2019, 221, 295-308. [CrossRef]

72. Zhang, H.; Wu, Q.; Cao, S.; Zhao, T.; Chen, L.; Zhuang, P.; Zhou, X.; Gao, Z. A novel protein elicitor (SsCut) from Sclerotinia sclerotiorum induces multiple defense responses in plants. Plant Mol. Biol. 2014, 86, 495-511. [CrossRef] [PubMed]

Publisher's Note: MDPI stays neutral with regard to jurisdictional claims in published maps and institutional affiliations.

(C) 2020 by the authors. Licensee MDPI, Basel, Switzerland. This article is an open access article distributed under the terms and conditions of the Creative Commons Attribution (CC BY) license (http://creativecommons.org/licenses/by/4.0/). 